九州大学学術情報リポジトリ

Kyushu University Institutional Repository

\title{
Combined Effects of Elevated Temperature and Carbon Dioxide on Geometry of Maize Leaves
}

Haraguchi, Tomokazu

Faculty of Agriculture, Saga University

Yuge, Kozue

Faculty of Agriculture, Kyushu Unviersity

Hao, Aimin

Graduate School of Bioresource and Bioenvironmental Sciences, Kyushu University

Nakano, Yoshisuke

他

https://doi.org/10.5109/4708

出版情報: 九州大学大学院農学研究院紀要. 51 (1)，pp.45-51，2006-02-01. Faculty of Agriculture， Kyushu University

バージョン：

権利関係: 


\title{
Combined Effects of Elevated Temperature and Carbon Dioxide on Geometry of Maize Leaves
}

\section{Tomokazu HARAGUCHI ${ }^{*}$, Kozue YUGE, Aimin HAO $^{2}$, Yoshisuke NAKANO, Ken MORI ${ }^{3}$ and Tomohisa YANO ${ }^{4}$}

\author{
Laboratory of Irrigation and Water Utilization, Division of Regional Environment Science, \\ Department of Bioproduction and Environmental Sciences, Faculty of Agriculture, \\ Kyushu University, Fukuoka 812-8581, Japan \\ (Received October 28, 2005 and accepted November 16, 2005)
}

\begin{abstract}
An accurate prediction of variations in water consumption from a field and in the crop growth affected by the climate change due to global warming is important for the continuous agricultural activities. Components of water consumption in a farmland, i.e. transpiration from the crop surface and evaporation from the soil surface, are influenced by the structure of crop canopy. In this study, the combined effects of elevated temperature and carbon dioxide $\left(\mathrm{CO}_{2}\right)$ concentration on the geometry and longevity of leaves of maize were examined through an experiment with growth chambers. Three treatments, i.e. TLCL (air temperature day/night: $28 / 22^{\circ} \mathrm{C}, \mathrm{CO}_{2}$ concentration: $\left.350 \mathrm{ppm}\right)$, TLCH $\left(28 / 22^{\circ} \mathrm{C}, 750 \mathrm{ppm}\right)$, and THCH $\left(32 / 26^{\circ} \mathrm{C}, 750 \mathrm{ppm}\right)$, were performed in different closed chamber respectively, and sixteen of maize (Zea mays L. cv. Pioneer G-98) planted in a pot were grown in each treatment. The cumulative thermal time from emergence of plant until the expansion of the $i$ th leaf became larger in the order, TLCH $<$ TLCL $<$ THCH. The longevity of the ith leaf became longer in the order, TLCL $<$ TLCH $<$ THCH. Area of the $i$ th leaf in THCH was clearly smaller than that in TLCL and TLCH.
\end{abstract}

\section{INTRODUCTION}

Global warming will cause more or less change in a climate of an agricultural area and must also influence environments of the crop growth such as soil moisture and nutrient contents and micrometeorology in a farmland. It is necessary to predict how the growth environment will change so that a man can continue agricultural activity coping with the climate change. Furthermore a prediction of variations in water consumption from a field and in the crop growth affected by the climate change is important for the continuous agricultural activities. The prediction makes it possible to plan the irrigation under the condition affected by global warming. If the amount of water available for agriculture at present is lower than that predicted for the condition the countermeasure such as selecting other cultivation crops and constructing an irrigation facility will be necessary.

Water consumption from a farmland, i.e. evapotranspiration, consists of transpiration from the crop surface and evaporation from the soil surface; both are affected

${ }^{1}$ Laboratory of Agricultural Water Supply and Management, Department of Agricultural Sciences, Faculty of Agriculture, Saga University, Saga 840-8502, Japan

${ }^{2}$ Laboratory of Irrigation and Water Utilization, Division of Regional Environment Science, Department of Bioproduction and Environmental Sciences, Graduate School of Bioresource and Bioenvironmental Sciences, Kyushu University

${ }^{3}$ Laboratory of Bioproduction and Environment Information Sciences, Division of Bioproduction and Environment Information Sciences, Department of Bioproduction and Environmental Sciences, Faculty of Agriculture, Kyushu University

${ }^{4}$ Arid Land Research Center, Tottori University

* Corresponding author (E-mail: tomh@cc.saga-u.ac.jp) by the structure of crop canopy. The growth and yield of crop are influenced by the conditions of the surrounding atmosphere and soil, e.g. Traore et al. (2000), Polly (2002). Therefore, the modeling of effects of the climate change on the growth of a plant and on the formation of a crop canopy is useful for estimating the influence of the climate change on evapotranspiration by using a simulation model.

Crop plants gather to make a canopy. The geometric structure of a crop canopy is characterized by such factors as planting density, leaf area density, and the structure of an individual plant characterized by the orientation, area, and direction of leaves and crop height. The characteristics of green leaf are necessary for evaluating the photosynthesis or transpiration. Area of green leaves of a plant, $A_{g}$, at a time $t$ is calculated as:

$$
A_{g}=A_{e}-A_{y}
$$

where $A_{e}$ is the cumulative area of parts which expanded until the time $t$ and $A_{y}$ is the cumulative area of parts which yellowed until the time $t$. The areas of expanded and yellowed part of a leaf can be expressed with the area of a fully expanded leaf and the ratios of the area of expanded and yellowed part to the fully expanded area. Therefore, the equation (1) can be rewritten as:

$$
A_{g}=\sum_{i=1}^{N} A_{\max , i}\left(R_{e, i}-R_{y, i}\right)
$$

where $A_{m a x ;}$ is the fully expanded area of the $i$ th leaf, $R_{e, i}$ and $R_{y, i}$ are the ratios of expanded and yellowed part of the $i$ th leaf, respectively. The number $i$ denotes the position of nod on which the leaf sprouts. $N$ is the total number of leaves of a plant. Dwyer et al. (1992) and Lizaso et al. (2003) have expressed the parameter $A_{\max , i}$ for maize (Zea mays L.) as a function of a nodal position. 
Temporal variation of area of green leaves of a plant can be modeled if the parameters in equation (2) are expressed with a function of meteorological elements such as air temperature and solar radiation. Lizaso et al. (2003) have taken into account the stress factors due to water, nutrient and oxygen shortage in the calculation for the expansion of a leaf. In this study, the combined effects of elevated temperature and carbon dioxide $\left(\mathrm{CO}_{2}\right)$ concentration on the geometry and longevity of leaves of maize, which is cultivated under various climate conditions in the world, were examined through an experiment with growth chambers.

\section{MATERIALS AND METHODS}

The experiment was conducted in three closed growth chambers at Biotron Institute of Kyushu University (E130 ${ }^{\circ} 4^{\prime}, \mathrm{N}_{3}^{\circ}{ }^{\circ} 38^{\prime}$ ), Japan. Air temperature and $\mathrm{CO}_{2}$ concentration in the chambers (treatments) were set as shown in Table 1. A set value of relative humidity was $70 \%$ in all chambers. Sixteen Wagner pots with an area of $0.05 \mathrm{~m}^{2}$ were placed in each chamber, and they were arranged with a density of 8 pots per square meter. Mixture of Andosols and Masa (sandy soil) (1:1 volume) was put into each pot with $10 \mathrm{~g}$ of chemical fertilizer (N-P-K; 16\%-16\%-16\%) as basal dressing. The soil-moisture characteristic curve of the

Table 1. Meteorological condition in chambers.

(Day time: 8 AM-8 PM)

\begin{tabular}{ccc}
\hline $\begin{array}{c}\text { Chamber No. } \\
\text { (Treatment) }\end{array}$ & $\begin{array}{c}\text { Air temperature }\left({ }^{\circ} \mathrm{C}\right) \\
\text { day/night }\end{array}$ & $\mathrm{CO}_{2}(\mathrm{ppm})$ \\
\hline $\begin{array}{c}1 \\
\text { (TLCL) } \\
2\end{array}$ & $28 / 22$ & 350 \\
$(\mathrm{TLCH})$ & $28 / 22$ & 700 \\
3 & $32 / 26$ & 700 \\
\hline
\end{tabular}

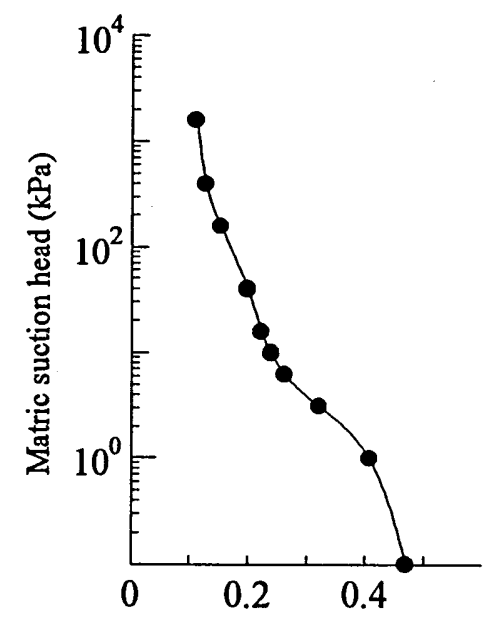

Volumetric water content

Fig. 1. Soil-moisture characteristic curve of the mixed soil. soil is shown in Fig. 1. The volume of the soil in a pot was about $0.011 \mathrm{~m}^{3}$. Readily available moisture, which is the difference of volumetric water content between the field capacity (suction of $6.19 \mathrm{kPa}$ ) and the wilting point $(390 \mathrm{kPa})$, was 0.135 .

Three seeds of maize (Zea mays L. cv. Pioneer G-98) were sown in each pot on June 11, 2004. Emergence of seeding occurred 3 days after sowing (DAS) in all treatments, and seedlings were thinned to one plant per pot five days after seeding emergence. The soil surface had been covered with white plastic beads since 10DAS for preventing soil surface evaporation. Irrigation water was applied through the PVC tube of inner diameter $30 \mathrm{~mm}$ that stuck into the soil surface. The change from the vegetative to reproductive period occurred at about $30 \mathrm{DAS}$. The silking and maturity stages were found on 58 and $96 \mathrm{DAS}$, respectively.

Observation of leaves was conducted for judging expansion and yellow changing of a leaf every 1-3 days. We counted up the number of leaves when half the area of a leaf expanded or yellowed following the definition of longevity by Lizaso et al. (2003). A pot was weighed before watering to check the soil moisture condition and to calculate the transpiration rate. On 27, 45, 58 and 96 DAS, four plants were sampled from each treatment for the measurement of biomass and leaf area. Pots were moved next position in a chamber to eliminate the effect of the structure of the chamber such as a shade of a frame on a wall after every weighing.

Air temperature and humidity were measured every 10 minutes using a humidity and temperature logger (Sensor: HA9630, Logger: HA3631; NIHON SHINTECH Co., Ltd.) in each chamber, and the amount of solar radiation was measured every 3 minutes with a pyranometer (LI-200SB, LI-COR, inc.) in the chamber 2 for the treatment TLCH.

\section{RESULTS AND DISCUSSION}

\section{Meteorology and soil moisture conditions}

The average of the daily mean temperature during the whole experiment period were 25,25 , and $29^{\circ} \mathrm{C}$ for treatment TLCL, TLCH, and $\mathrm{THCH}$, respectively. Relative humidity in TLCH was unexpectedly higher than the expected value. There was no significant difference in the amount of solar radiation among the chambers. Daily solar radiation did not exceed 10.0 MJ $\mathrm{m}^{-2} \mathrm{~d}^{-1}$ (Fig. 2). The average of it in TLCH during the whole experiment period was $5.83 \mathrm{MJ} \mathrm{m}^{-2} \mathrm{~d}^{-1}$.

Figure 3 shows the time courses of volumetric water contents obtained from the change of a pot weight. These values denote the mean water content over the whole soil in a pot. Mean soil moisture in a pot came to high content immediately after an irrigation. Soil moisture was kept in a relatively lower level for all treatments until 30DAS because of less amounts of irrigation water and transpiration loss. The water content near the soil surface, however, was actually high during this period. The water content in $\mathrm{THCH}$ was less than the value that corresponded to the wilting point $(390 \mathrm{kPa})$ at 


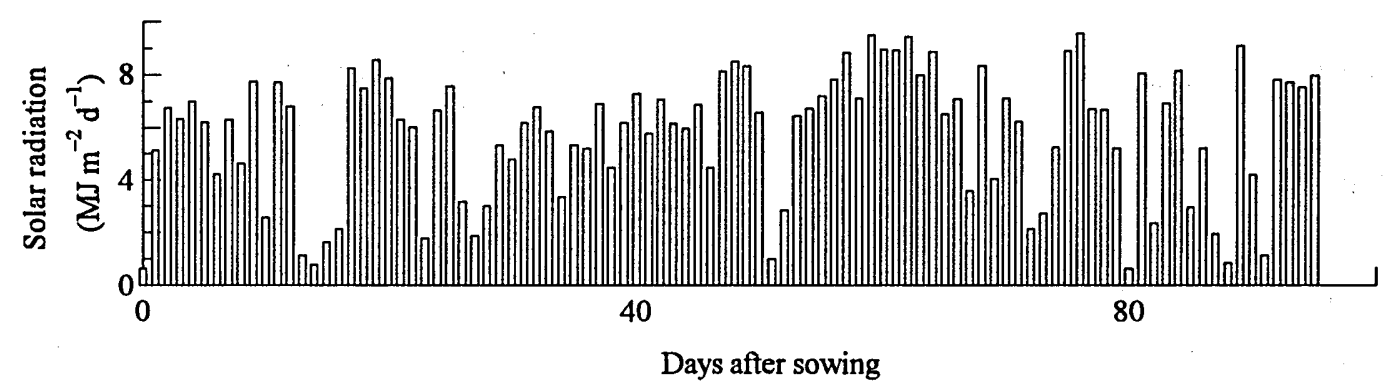

Fig. 2. Change of daily solar radiation observed in Chamber 2.

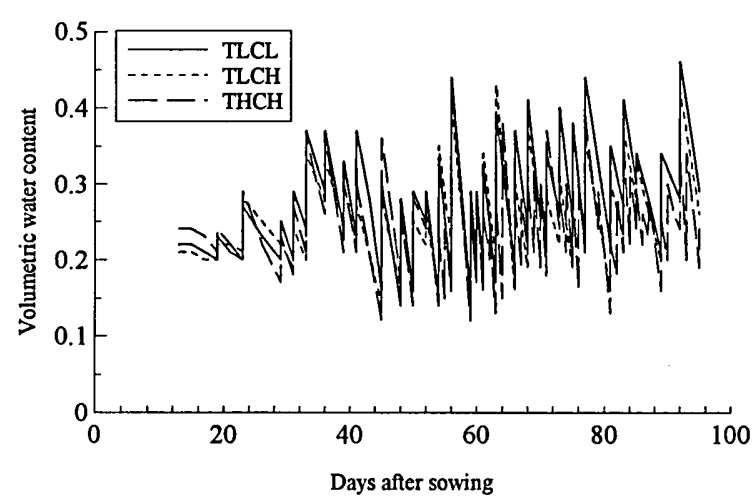

Fig. 3. Time courses of soil moisture.

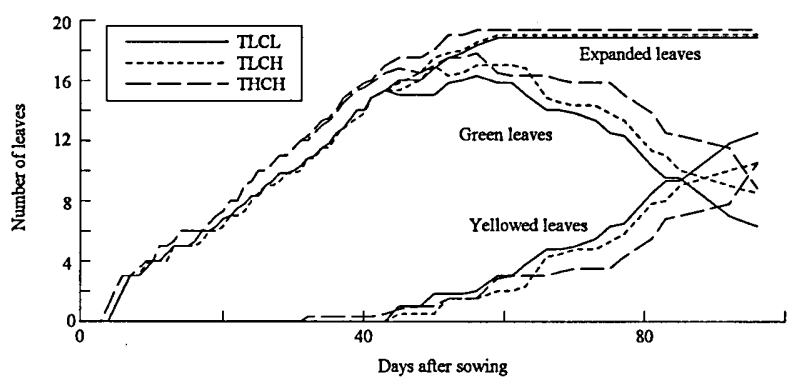

Fig. 4. Time courses of number of expanded, green, and yellowed leaves.

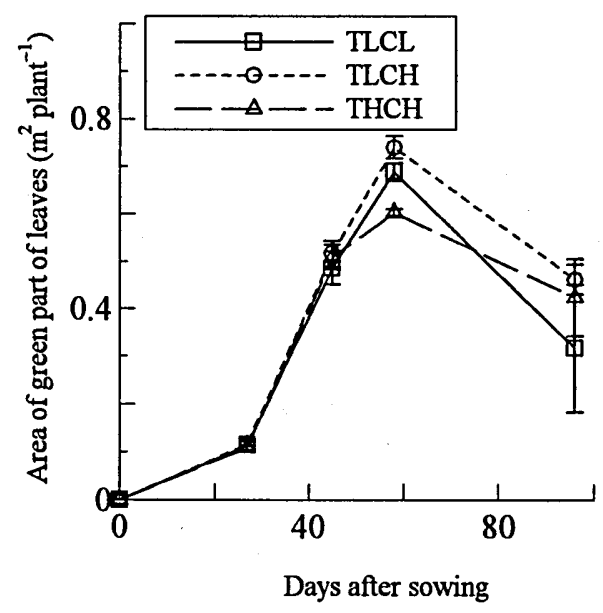

Fig. 5. Time courses of area of green leaves of a plant.
45 and 59DAS, while that in TLCL and TLCH was never below this value.

\section{Number and area of leaves (for a plant)}

Figure 4 demonstrates the time courses of the number of expanded, green, and yellowed leaves in the treatments. These values were the average for the four plants, which were sampled at $96 \mathrm{DAS}$. The number of green leaves was obtained by subtracting the number of yellowed leaves from that of expanded leaves. The number of expanded leaves in $\mathrm{THCH}$ was larger than that in TLCL and TLCH by 60 DAS although emergence of seeding occurred at the same day in all treatments. The mean numbers of expanded leaves for TLCL, TLCH and $\mathrm{THCH}$ were $18.8,19.0$ and 19.3 , respectively. The appearance of the first yellowed leaf in THCH was earlier than that in TLCL and TLCH. The number of yellowed leaves in THCH was smaller than that in TLCL and TLCH from 60DAS. The number of green leaves at the maturity stage became larger in the order, TLCL $<$ $\mathrm{TLCH}<\mathrm{THCH}$. This resulted from the fact that the longevity of a leaf became longer in the same order.

The total green areas per plant at the four sampling times are show in Fig. 5. The vertical bar on a symbol denotes standard deviation. There was no significant difference among treatments at the first and second samplings (27 and 45 DAS). From the silking period (the third sampling, 58DAS) to the maturity stage (the fourth sampling, 96 DAS), there was clear difference due to the effects of the growth environment. The decrease in the green leaf area for THCH was smaller than that in other treatments during the period from 58 to 96 DAS. This difference among treatments might occur due to the differences in the longevity discussed above and in the areas of a leaf discussed below.

\section{Growth of leaves}

The effective temperature, which is obtained by subtracting the base temperature, is used for evaluating the effect of air temperature on the growth and development of plant. The base temperature is adopted depending on species, variety and growth stage of a plant. As for maize, Borrás et al. (2003) have used the thermal time from the silking for which the base temperature of $0^{\circ} \mathrm{C}$ was used to evaluate the growth of kernel, Verheul et al. (1996) have used $6^{\circ} \mathrm{C}$ for evalu- 


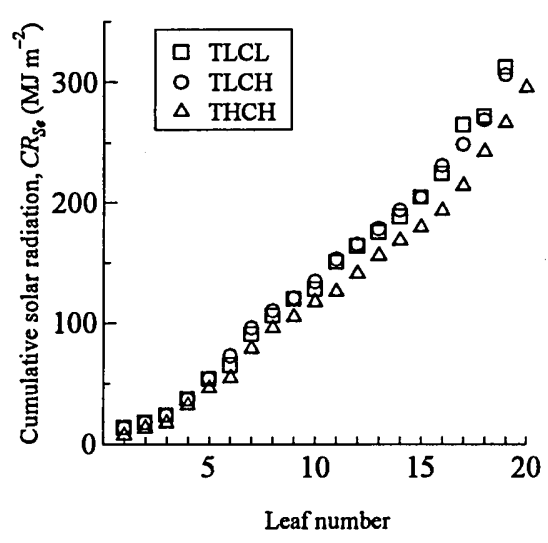

a) Cumulative solar radiation

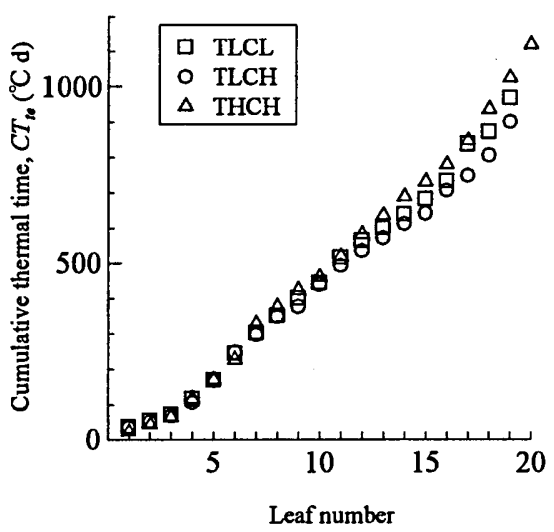

b) Cumulative thermal time

Fig. 6. Cumulative solar radiation and cumulative thermal time from emergence of plant until expansion of each leaf.

ating the rate of leaf appearance under chilling condition, Assuero et al. (2004) have used $10^{\circ} \mathrm{C}$ for the evaluation of the effect of phosphorus-deficient on growth of leaves while most study (e.g. Wilson et al., 1995; Machado et al., 2002; Gungula et al., 2003) have used the base temperature of $8^{\circ} \mathrm{C}$.

The thermal time of a day was calculated by multiplying the effective temperature and one day. The effective temperature was the difference between daily mean air temperature and a base temperature of $8^{\circ} \mathrm{C}$. The cumulation of the thermal time and daily solar radiation from emergence of plant until the expansion of the $i$ th leaf for the fourth-sampling plants, $C R_{s e}$ and $C T_{t}$, are illustrated in Fig. $6 \mathrm{a}$ and $6 \mathrm{~b}$, respectively. There was no significant difference in the relations among three treatments for the first - sixth leaf. The differences among treatments increased with increasing the leaf number, $L N$. $C R_{S e}$ of a leaf of which $L N$ was $7-19$ in THCH was smallest while $C T_{t e}$ of that leaf was largest. $C R_{S e}$ in TLCH was almost equal to that in TLCL, and $C T_{t e}$ in TLCH was smaller than that in TLCL for the eleventh - nineteenth leaf.

The cumulative value of solar radiation and thermal

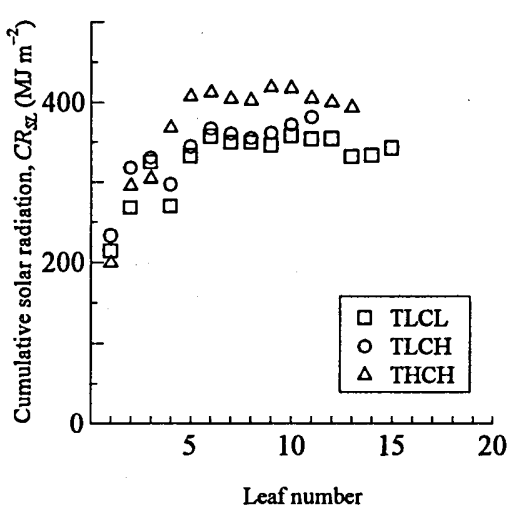

a) Cumulative solar radiation

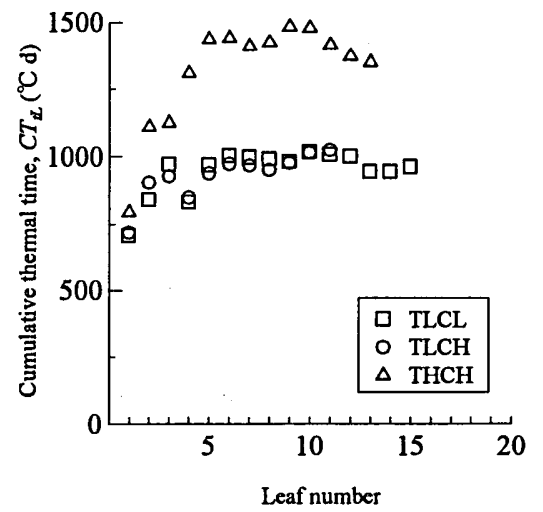

b) Cumulative thermal time

Fig. 7. Cumulative solar radiation and thermal time during longevity period of each leaf.

time during the longevity period of the $i$ th leaf, $C R_{S L}$ and $C T_{t}$, was shown in Fig. $7 \mathrm{a}$ and $7 \mathrm{~b}$. The longevity period is the period from the expansion to yellow coloring of a leaf. $C R_{S L}$ and $C T_{t L}$ for a leaf of larger $L N$ are not illustrated in this figure because the yellow coloring of the leaves was not recognized until the harvest day (the last sampling). $C R_{S L}$ of a leaf of which $L N$ was 5-11 and $C T_{t L}$ in THCH was larger than that in TLCL and TLCH because of the longest longevity; the average longevity of leaves in TLCL, TLCH, and THCH was 57, 59 and 68 days, respectively. We can see the tendency that $C R_{S L}$ and $C T_{L L}$ increased with the increasing $L N$ for the first fifth leaf and slightly decreased for other leaves.

Figures 8 and 9 show the length and maximum width of a leaf in TLCL, TLCH and THCH at four samplings, i.e. 27, 45, 58 and $96 \mathrm{DAS}$. The length became longer from 27 to $45 \mathrm{DAS}$ and from 45 to $58 \mathrm{DAS}$ for some $L N$ due to extend of a leaf. There was no significant difference in the distribution of a leaf length between plants sampled at 58 and 96 DAS. The size of the maximum width of the $i$ th leaf varied little from a sampling to next one although some leaves did not fully expand for all treatments. The length and maximum 


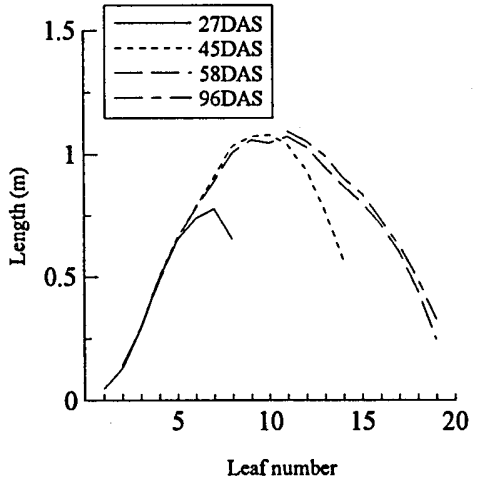

a) TLCL

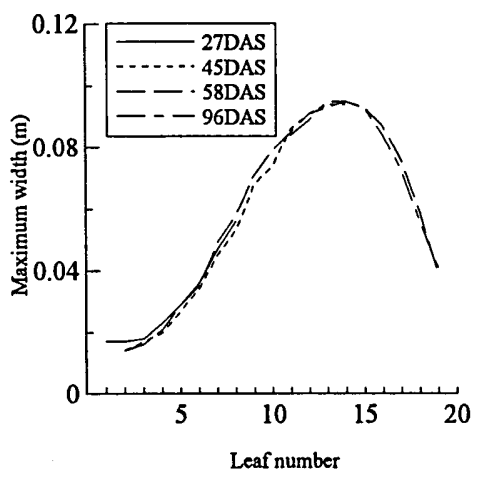

a) TLCL

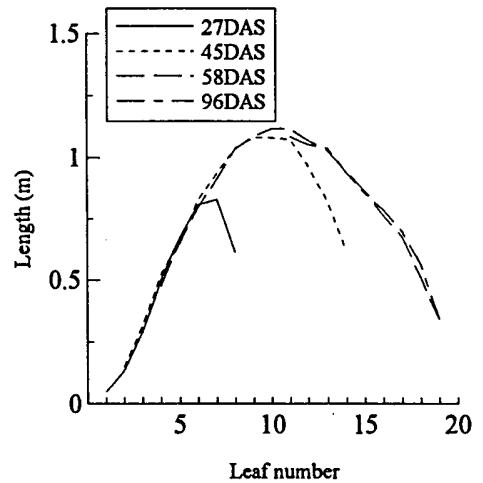

b) TLCH

Fig. 8. Changes in length of leaf.

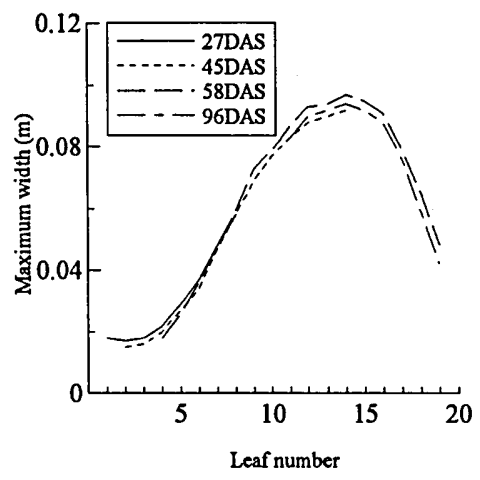

b) $\mathrm{TLCH}$

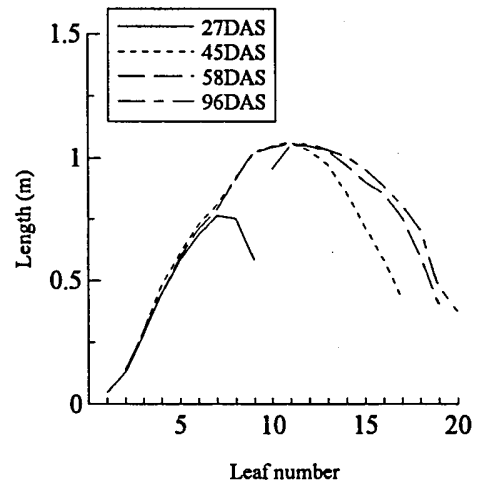

c) $\mathrm{THCH}$

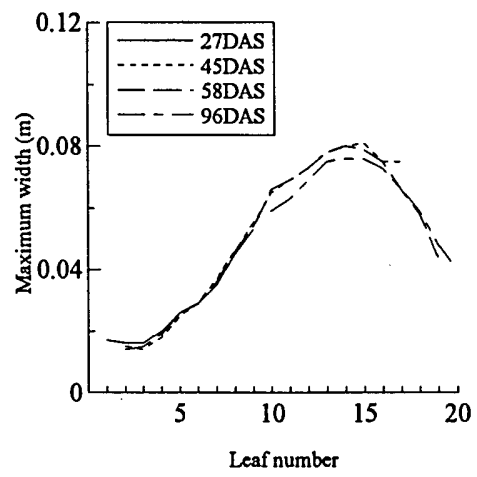

c) $\mathrm{THCH}$

Fig. 9. Changes in maximum width of leaf.

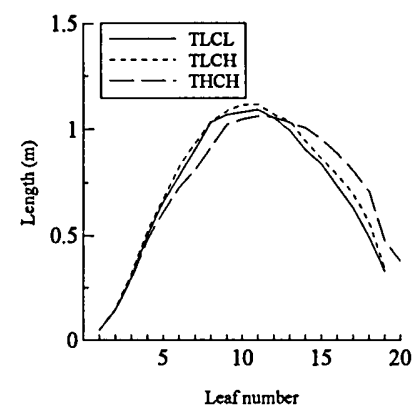

a) Length

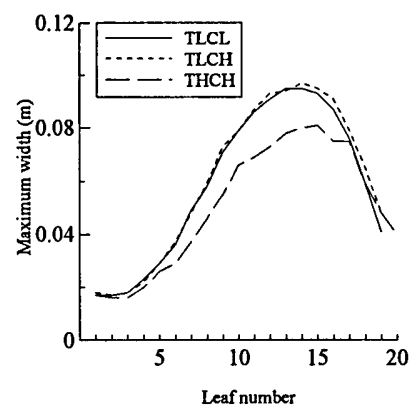

b) Maximum width

Fig. 10. Length and maximum width of fully expanded leaf. width of a fully expanded $i$ th leaf are shown in Fig. 10a and $10 \mathrm{~b}$, respectively. The length and maximum width in TLCH were slightly larger than that in TLCL. The length in THCH was smaller for the leaves of 1-11 $L N$ and was larger for the leaves of 14-19 $L N$ than TLCL and TLCH. The maximum width in THCH was clearly smaller than that in TLCL and TLCH.

Area of green part of the ith leaf at the 27, 45, 58 and $96 \mathrm{DAS}$ in TLCL, TLCH and THCH are shown in Fig. $11 \mathrm{a}, 11 \mathrm{~b}$ and $11 \mathrm{c}$, respectively. Area of a leaf that located in higher nodal position of shoots sampled at 27 and 45 DAS became larger until the next sampling in all treatments. There was little change from 58 to $96 \mathrm{DAS}$ in TLCH, while some leaves became larger in TLCL and THCH during this period. Figure 12 shows areas of the $i$ th leaf which fully expanded in all treatments. Area of the $i$ th leaf in TLCH was equal to that in TLCL for the first - eighth leaf and was larger a little than that in TLCL for the leaf of which $L N$ was 9-19. Area of the $i$ th leaf in THCH was clearly smaller than that in TLCL and TLCH for the leaf of which $L N$ was 1-14. This reduction of leaf area in THCH must have caused not by water stress, but by higher air temperature.

The ratios of the area of an expanded leaf to the product of maximum width and length of the leaf in all treatments are shown in Fig. 13. There was not significant difference in the ratio among treatments except for the fifteenth - nineteenth leaf, for which the area in 


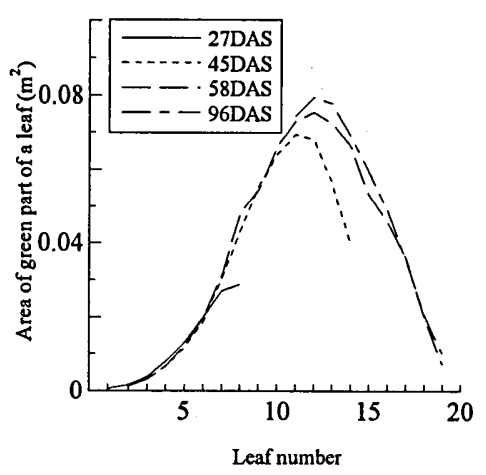

a) TLCL

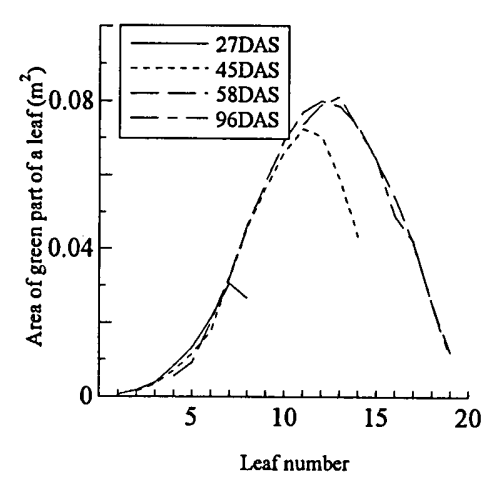

b) $\mathrm{TLCH}$

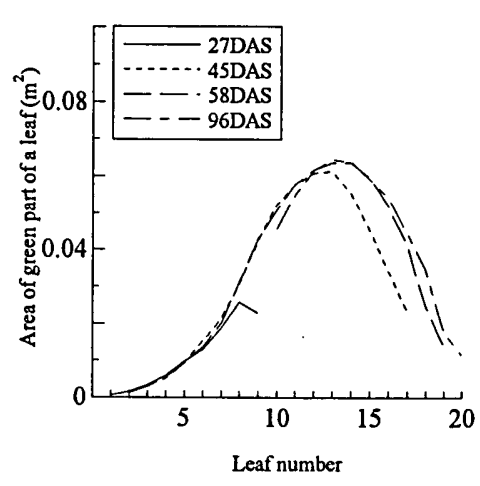

c) $\mathrm{THCH}$

Fig. 11. Changes in area of green part.

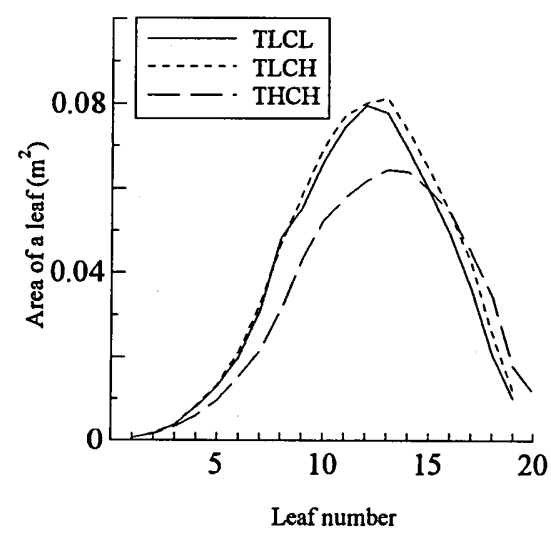

Fig. 12. Area of fully expanded leaf.

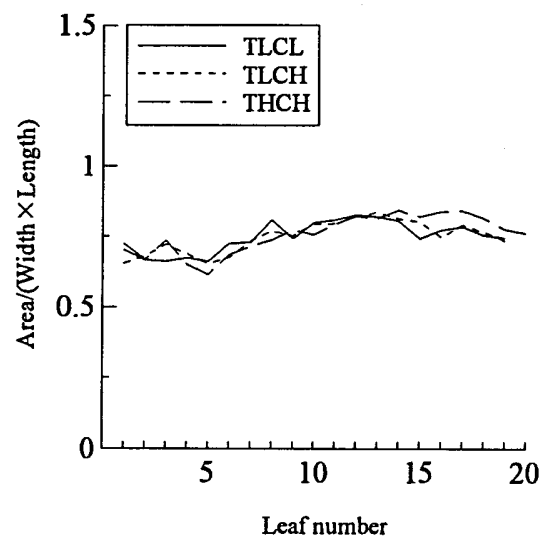

Fig. 13. Ratio of the area to the product of maximum width and length of expanded leaf.
THCH was clearly larger than that in TLCL and TLCH. The relationship between the ratio and $L N$ can be described in a single formula for all treatments, and an area of the $i$ th leaf can be estimate by using the formula, measurements of maximum width and length, and its $L N$.

\section{CONCLUSIONS}

The experiment was conducted to examine the combined effects of elevated temperature and carbon dioxide $\left(\mathrm{CO}_{2}\right)$ concentration on the geometry and longevity of leaves of maize with growth chambers. Three treatments, i.e. TLCL (air temperature day/night: $28 / 22^{\circ} \mathrm{C}, \mathrm{CO}_{2}$ concentration: $\left.350 \mathrm{ppm}\right)$, TLCH $\left(28 / 22^{\circ} \mathrm{C}\right.$, $750 \mathrm{ppm})$, and $\mathrm{THCH}\left(32 / 26^{\circ} \mathrm{C}, 750 \mathrm{ppm}\right)$, were performed in different closed chamber respectively, and sixteen of maize (Zea mays L. cv. Pioneer G-98) planted in a pot were grown in each treatment. The cumulative thermal time from emergence of plant until the expansion of the $i$ th leaf became larger in the order, TLCH $<$ TLCL $<$ THCH. The longevity of the $i$ th leaf became longer in the order, TLCL $<\mathrm{TLCH}<\mathrm{THCH}$. Area of the $i$ th leaf in THCH was clearly smaller than that in TLCL and TLCH.

\section{ACKNOWLEDGEMENT}

This is a partial contribution from the ICCAP Project (Impact of Climate Changes on Agricultural Production System in the Arid Areas), being promoted by the Research Institute for Humanity and Nature (RIHN) and the Scientific and Technical Research Council of Turkey (TÜBİTAK).

\section{REFERENCES}

Assuero, S. G., A. Mollier and S. Pellerin 2004 The decrease in growth of phosphorous-deficient maize leaves related to a lower cell production. Plant, Cell and Environ., 27: 887-895

Borrás, L., M. E. Westgate and M. E. Otegui 2003 Control of kernel weight and kernel water relations by post-flowering source-sink ratio in maize. Ann. Bot., 91: 857-867

Dwyer, L. M., D. W. Stewart, R. I. Hamilton and L. Houwing 1992 Ear position and vertical distribution of leaf area in corn. 
Agron. J., 84: 430-438

Gungula, D. T., J. G. Kling and A. O. Togun 2003 CERES-Maize predictions of maize phenology under nitrogen-stressed conditions in Nigeria. Agron. J., 95: 892-899

Lizaso, J. I., W. D. Batchelor and M. E. Westgate 2003 A leaf area model to simulate cultivar-specific expansion and senescence of maize leaves. Field Crops Res., 80: 1-17

Machado, S., E. D. Bynum, Jr., T. L. Archer, R. J. Lascano, L. T. Wilson, J. Bordovsky, E. Segarra, K. Bronson, D. M. Nesmith and W. Xu 2002 Spatial and temporal variability of corn growth and grain yield: Implications for site-specific farming. Crop Sci., 42: 1564-1576

Polly, H. W. 2002 Implications of atmospheric and climatic change for crop yield and water use efficiency. Crop Sci., 42 : $131-140$

Traore, S. B., R. E. Carlson, C. D. Pilcher and M. E. Rice 2000 Bt and non-Bt maize growth and development as affected by temperature and drought stress. Agron. J., 92:1027-1035

Verheul, M. J., C. Picatto and P. Stamp 1996 Growth and development of maize (Zea mays L.) seedling under chilling conditions in the field. Europ. J. of Agron., 5:31-43

Wilson, D. R., R. C. Muchow and C. J. Murgatroyd 1995 Model analysis of temperature and solar radiation limitations to maize potential productivity in a cool climate. Field Crops Res., 43: 1-18 